\title{
Considering Environmental Externalities in Technology Selection: the Case of Urban Buses for Athens
}

\author{
Dimitrios A. Georgakellos \\ Department of Business Administration, University of Piraeus \\ 80 Karaoli and Dimitriou Street, 18534 Piraeus, Greece
}

\begin{abstract}
The present study proposes a procedure for considering the environmental externalities in technology selection decision-making, based on the outcome of Life Cycle Assessments. Currently, even if there are several methods available for technology selection and purchasing, almost all of them seem to ignore the external cost associated with the candidates. The main features of the proposed model are its simplicity and flexibility, while it leads to an easily comparable or incorporated in other models single value. An application of this procedure concerning the comparison of two urban buses, fueled by different fuels for the city of Athens, is also included.
\end{abstract}

Key words: Technology Selection, Environmental Externalities, LCA, Urban Buses, Athens

\section{INTRODUCTION}

In general, all selection mechanisms reflect somehow the selection of what creates most net value to the buyer. Therefore, selection reflects the criteria used by customers, shareholders and internal stakeholders [1]. Specifically, technology selection involves decisionmakings that are critical to the profitability and growth of a company in the increasing competitive global scenario. These selection processes require the analysis of a large number of technical and economic (tangible) as well as analytical (intangible) factors in a decision support environment [2]. Many precision-based methods for technology selection have been developed. Most of them are based on traditional supplier selection methods and purchasing decision models. In this context, contemporary Operations Research (OR) offers a range of methods and techniques that may support the purchasing decision-maker in many technology selection processes. Examples of such techniques are multi-criteria decision aid, problem structuring approaches, mathematical programming and data mining techniques. OR-models may enhance the effectiveness of purchasing decisions by: (a) aiding the purchaser in solving the "right problem", e.g. refraining from dropping a supplier when the delivery problems are actually caused by feeding the supplier with outdated information; (b) aiding the purchaser in taking more and relevant alternatives criteria into account when making purchasing (management) decisions, e.g. more long-term considerations when deciding on makeor-buy; (c) aiding the purchaser to more precisely model the decision situation, e.g. dealing specifically with intangible factors and group decision-making [3].

As it is mentioned above, all selection techniques are based on a number of criteria, tangible (technical or economic) and intangible (analytical). Traditionally,
Net Present Value (NPV), Internal Rate of Return (IRR), Payback Period (PB) and Return On Investment (ROI) have been adopted by researchers to evaluate the economic factors [2]. It is remarkable that the essence of all economic evaluation is a discounted cash flow analysis. However, in carrying out such an evaluation, it will be essential to remember that correct selection of the discount rate may be crucial. Its choice can easily change the ranking of projects, making one or another appears best depending on the rate used [4]. On the other hand, to evaluate analytical factors, Analytical Hierarchy Process (AHP), utility measurement, portfolio models and systems value analysis are some examples of techniques that can be used for this purpose. Most of the methods mentioned above are based on the concept of accurate measurement and crisp evaluation, i.e. the measuring values must be exact and numerical. However, owing to the availability and uncertainty of information, it is very difficult to obtain the exact assessment data such as investment cost, gross income, expenses, depreciation, salvage value, interest rate, flexibility, productivity, quality, etc. [2]. Some times, technology selection problems are incorporated in the facility location and capacity acquisition models. Given a set of alternative facility locations, a set of alternative manufacturing technologies and a set of markets to be served, the facility location and technology acquisition problem involves simultaneously locating an undetermined number of new facilities and deciding the type and amount of the technologies to be acquired at each facility so as to minimize the total cost of serving the market demand $[5,6]$.

All the above-mentioned approaches of technology selection consider factors, no matter tangible or intangible, which seem to focus almost exclusively on what creates most net value to the buyer of technology 
while the environmental externalities associated with every choice, in most of the cases, are not taken into consideration. An externality is a third party effect associated with production or consumption. If the external effect generates costs to a third party it is a negative externality. Of interest to environmental economists are externalities that damage the atmosphere, water supply, natural resources and the overall quality of life $[7,8]$. In other words, the selection process is based, almost always, on criteria like net price, technical performance, capacity, quality, delivery or service, while criteria arising from the environmental performance of the candidates and the subsequent externalities associated with their production and use are disregarded. Because of this fact, the relevant literature has been, to our knowledge, extremely limited. Thus, only in a recent study, life cycle electricity and environmental impacts for computer tape drives have been combined with TCO philosophy. However, the aim of this, even unique, attempt was not to give a specific decision tool but just to make an estimate of the different impacts of manufacturing versus use-phase impacts of this product [9].

In this context, a procedure for the integration of the environmental externalities in technology selection process is presented in the next sections. This is being achieved by the use of the Life Cycle Assessment (LCA) theory. Moreover, an application of this procedure concerning the selection of two urban buses, fueled by different fuels, for the city of Athens is included.

\section{MATERIALS AND METHODS}

The possibility of taking into account on a comprehensive and objective basis the environmental externalities of alternative options in technology selection process requires consideration of the overall environmental burdens generated by them during their entire life-cycle. In other words, the whole process from the cradle to grave, which includes the different stages of the candidates life-cycle such as the extraction and processing of raw materials, manufacturing, transportation, distribution, use and re-use, maintenance, recycling and final disposal, is to be studied. The concept of Life Cycle Assessment has been developed for this purpose and widely used in recent years in many different applications. Thus, the LCA approach is being used in the present work as well in order to provide a tool that intends to integrate the environmental performance and the subsequent external cost associated with the candidates' production and use in technology selection decision-making.

More precisely, the model uses the findings of the inventory component of Life Cycle Assessment. In LCI, a model is made of the complex technical system concerning production, transportation, use and disposal of a product. The LCA model is necessary to calculate the total energy and resource use as well as the total environmental releases from the overall system. This results in a flow sheet or a process tree with all the relevant processes. For each process, all the relevant inflows and outflows are collected. This step consists of summing the energy, raw materials and various emission values that result from the energy and material flows, for each stage of the product's life cycle. The LCA model defines numerically the relationships of the individual subsystems to each other in the production, use and disposal of the final product. The real hard study in any inventory is the data collection and data treatment itself. There are a number of data sources: data supplied in commercial databases, data supplied by industry sectors, data supplied by universities and research centres, national database projects as they develop in several countries, literature data in general (especially data that describe processes) and specialized internet sites [10,11].

The outcome of an LCI could cover a long list of environmental impacts (inflows and outflows) such as energy consumption by fuel type or energy source, raw and auxiliary materials consumption, atmospheric emissions, waterborne waste, solid waste etc. These environmental impacts are being used by the proposed here model for integrating the environmental externalities of candidates in technology selection projects according to the procedure that follows.

Assuming that " $\mathrm{r}$ " candidates are under examination and comparison and that, for each candidate, there are "n" environmental impacts that have been resulted from the inventory phase, then for every candidate and for each one of its environmental impacts $\mathrm{EI}_{\mathrm{i}, \mathrm{k}}(\mathrm{i}=1, \ldots, \mathrm{n}$ and $\mathrm{k}=1, \ldots, \mathrm{r})$, an ecological coefficient $\mathrm{EC}_{\mathrm{i}, \mathrm{k}}$ is calculated as follows:

$E C_{i, k}=\frac{E I_{i, k}}{A v E I_{i, k}} \quad$ for $\mathrm{i}=1, \ldots, \mathrm{n}$ and $\mathrm{k}=1, \ldots, \mathrm{r}$

where:

$\mathrm{EI}_{\mathrm{i}, \mathrm{k}}$ is the environmental impact $\mathrm{i}$ for the candidate $\mathrm{k}$,

$\mathrm{EC}_{\mathrm{i}, \mathrm{k}}$ is the ecological coefficient $\mathrm{i}$ for the candidate $\mathrm{k}$ and

$A v E I_{i, k}$ is the estimate of the average environmental impact $i$ for a typical product or process in the industrial or economic sector of the candidate $\mathrm{k}$.

Afterwards, for every candidate $\mathrm{k}(\mathrm{k}=1, \ldots, \mathrm{r})$ under examination, an ecological grade is calculated as follows:

$E G_{k}=\sum_{i=1}^{n} x_{i} E C_{i, k} \quad$ for $\mathrm{k}=1, \ldots, \mathrm{r}$

where:

$\mathrm{EG}_{\mathrm{k}}$ is the ecological grade of the candidate $\mathrm{k}$ and 
$x_{i}$ is the weighing factor corresponding to the environmental impact $\mathrm{i},\left(\sum_{i=1}^{n} x_{i}=1\right)$

If no specific definition of $x_{i}$ is required, then one could consider that:

$$
x_{i}=\frac{1}{n} \quad \text { for } \mathrm{i}=1, \ldots, \mathrm{n}
$$

However, in certain cases the definition of the weighing factors of the model $\left(\mathrm{x}_{\mathrm{i}}\right)$ may be very important for the reason that it may affect the results. Depending on the case, assigning specific values to these factors, even if required, may be tough or may need high accuracy. In these cases, a sensitivity analysis should be performed. Subsequently, for each candidate $\mathrm{k}(\mathrm{k}=1, \ldots, \mathrm{r})$ its relative external cost is calculated, as follows:

$$
R E C_{k}=E G_{k} A v E C_{k} \quad \text { for } \mathrm{k}=1, \ldots, \mathrm{r}
$$

where:

$\mathrm{REC}_{\mathrm{k}}$ is the relative external cost of the candidate $\mathrm{k}$, $\mathrm{EG}_{\mathrm{k}}$ is the ecological grade of the candidate $\mathrm{k}$ and $\mathrm{AvEC}_{\mathrm{k}}$ is the average external cost of a typical product or process in the industrial or economic sector of the candidate $\mathrm{k}$.

Finally, the relative external cost could be used as the exclusive basis for the comparative appraisal of the candidates (in such a choice the best candidate is this one which has the lowest relative external cost $\mathrm{REC}_{\mathrm{k}}$ ), or it could be easily integrated in most of the technology selection decision methods (like these ones presented in the previous section). For instance, $\mathrm{REC}_{\mathrm{k}}$ can be considered, together with other costs that incurred throughout the candidates' life cycle and are include in a TCO-based model, to adjust the unit price quoted. Likewise, it can be used as one more criterion, among other criteria used, in a linear weighting model, or as one more variable in any other similar method.

From the above description of the model it is evident that, for each candidate " $\mathrm{k}$ " under comparison, one should know the Average External Cost $\left(A v E C_{k}\right)$ as well as the "n" Average Environmental Impacts $\left(A v E I_{i, k}\right)$ associated with this cost, in order to apply it. This may be not so easy for certain projects. However, the relevant literature can provide these data for a number of products, processes and activities and this number seems to grow steadily. In addition, numerous databases of national and international organizations, research centers, universities, Internet sites etc are able to provide them as well. For example, such a database is the Economic Input Output-Life Cycle Assessment (EIOLCA) software concerning 485 commodity sectors in the USA that has been developed by Carnegie Mellon University Green Design Initiative. The EIOLCA model traces out the various economic transactions, resource requirements and environmental emissions required for a particular product or service $[12,13]$. Other similar, even more specific, databases have been developed within the framework of INFRAS/IWW project and the ExternE project concerning the external cost of transport in Western Europe [14,15], the ExternE projects concerning the external cost of electricity generation in Greece and other European countries etc. [16]. Therefore, collecting the necessary data $\left(\mathrm{AvEC}_{\mathrm{k}}\right.$ and $\left.\mathrm{AvEI}_{\mathrm{i}, \mathrm{k}}\right)$ from databases similar to the above mentioned or from any other appropriate source (reports, studies, papers etc.) from the general literature, together with the findings from Life Cycle Inventories associated with the particular candidates, one can take into consideration, through the proposed here procedure, the environmental externalities in a technology selection project.

The Case of Urban Buses for Athens: The methodology application presented in this section is concerned with the selection of two urban buses (a diesel one and a similar fueled by natural gas) for the city of Athens. The selection is based on the comparison of the environmental externalities associated with them. This application should be a part of a technology selection and purchasing project where the environmental externalities of candidates are being considered in decision-making, together with usual criteria (e.g. technical specifications, price, guarantee etc.) that can be taken into account by, appropriate for this purpose, decision models. The environmental criteria in such a project may be of the same importance as this of other common criteria in purchasing decisionmaking, since air pollutant emissions of road transport is a very serious issue in urban areas.

Although energy use and atmospheric pollution from road transport in Greece have been the subject of many studies from national and international research groups during the past decade, specific data concerning the external cost of urban buses in Athens, to our knowledge, are not available. Therefore, for the purposes of our case, relevant data that have been estimated for the city of Paris are used, after being properly adapted. More precisely, according to an estimation of Rabl [17], the total damage cost in Paris is $1.27 € / \mathrm{km}$ for the diesel bus and $0.23 € / \mathrm{km}$ for the bus fueled by natural gas. The estimation of these external costs has been based on a life cycle assessment comparing diesel buses with buses fueled by natural gas, presented in the same study. For buses the life cycle includes not only the utilization phase but also upstream and downstream phases, such as the production of the fuel, the fabrication of the buses and the disposal of the buses at the end of their useful life. The inventory of emissions of pollutants is presented in Table 1. Using this data, the damage cost estimate is quantified for the two buses under examination. The question is how can the damage costs be transferred to 
Table 1: Life Cycle Inventory Emissions in $\mathrm{g} / \mathrm{km}$ of a Diesel Bus and a Bus Fueled by Natural Gas

\begin{tabular}{lcc}
\hline Air pollutant & Diesel bus & Natural gas bus \\
\hline Carbon dioxide $\left(\mathrm{CO}_{2}\right)$ & 1.675 & 1.710 \\
Carbon monoxide $(\mathrm{CO})$ & 6.8 & 6.1 \\
Methane $\left(\mathrm{CH}_{4}\right)$ & 0.8 & 15.4 \\
Non-Methane Volatile Organic Compounds (NMVOC) & 3.95 & 1.46 \\
Nitrogen oxides $\left(\mathrm{NO}_{x}\right)$ & 26.4 & 8.4 \\
Sulphur dioxide $\left(\mathrm{SO}_{2}\right)$ & 3.4 & 2.6 \\
Particulate matters $(\mathrm{PM})$ & 0.79 & 0.14 \\
\hline
\end{tabular}

Table 2: Air Pollutants' Emissions in $\mathrm{g} / \mathrm{kWh}$ Associated with the Use of the Two Candidate Buses

\begin{tabular}{lcc}
\hline Air pollutant & Diesel bus & Natural gas bus \\
\hline Carbon monoxide $(\mathrm{CO})$ & 3 & 2.16 \\
Methane $\left(\mathrm{CH}_{4}\right)$ & 0.65 & 0.015 \\
Non-Methane Volatile Organic Compounds (NMVOC) & 0.4 & 0.004 \\
Nitrogen oxides $\left(\mathrm{NO}_{\mathrm{x}}\right)$ & 2 & 0.43 \\
Particulate matters $(\mathrm{PM})$ & 0.02 & 0.003 \\
\hline
\end{tabular}

Table 3: Emissions in g/GJ due to Fuel Production and Distribution

\begin{tabular}{lrlccccl}
\hline \multicolumn{1}{l}{} & $\mathrm{CO}_{2}$ & $\mathrm{CO}$ & $\mathrm{CH}_{4}$ & $\mathrm{NMVOC}$ & $\mathrm{NO}_{\mathrm{x}}$ & $\mathrm{SO}_{2}$ & $\mathrm{PM}$ \\
\hline Diesel & & & & & & & \\
Production & 6700 & 4.6 & 15.7 & 87.8 & 35.8 & 44.9 & 1.0 \\
Distribution & 110 & 0.33 & 0.14 & 0.28 & 1.25 & 0.45 & 0.11 \\
Total & 6800 & 4.9 & 15.8 & 88.1 & 37.1 & 45.4 & 1.1 \\
Natural gas & & & & & & & \\
Extraction of natural gas & 1600 & 1 & 20 & 11 & 4.1 & 2 & 0 \\
Distribution & 0 & 0 & 198 & 16 & 0 & 0 & 0 \\
Service stations & 2500 & 0.4 & 5.7 & 0.5 & 6.5 & 14.9 & 0.8 \\
Total & 4100 & 1.4 & 223.7 & 27.5 & 10.6 & 16.9 & 0.8 \\
\hline
\end{tabular}

other cities? To the extent that the costs, other than global warming, arise mostly from health impacts, they are proportional to the size of the affected population weighted by the respective concentration increments. For precise results one would have to repeat the analysis based on local meteorological and population data, but for a rough first estimation one can use the following rule of thumb: for primary pollutants emitted by vehicles in cities the damage cost is roughly proportional to the population of the conurbation while for secondary pollutants the damage cost is roughly proportional to the average regional population density within a radius of 500-1000 km [17]. Here the populations of the metropolitan areas are approximately 10 million for Paris and 4 million for Athens. Thus, according to the rule, an external cost in Athens would be about $40 \%$ of a corresponding external cost in Paris. However, considering also that (a) the ratios of the average emission factors of a petrol vehicle in Athens related to Paris are (Paris = 1) 0.72 for PM, 0.5625 for $\mathrm{NO}_{\mathrm{x}}, 2.04$ for $\mathrm{SO}_{2}$ and 1.07 for $\mathrm{CO}_{2}$ [15.18]; as well as that (b) the contribution of air pollutants of a diesel vehicle to the total damages in urban areas in Greece is $96,2 \%$ for $\mathrm{PM}, 0,8 \%$ for $\mathrm{NO}_{\mathrm{x}}, 2 \%$ for $\mathrm{SO}_{2}$ and $1 \%$ for $\mathrm{CO}_{2}$ [19], then one could assume that the particular external cost in Athens would about $75 \%$ of the corresponding external cost in Paris. In the present application, combining the two estimations (40 and $75 \%$ ), we accept the external cost associated with the buses under examination in Athens is $60 \%$ of the corresponding external cost in Paris. Therefore, the average external cost $\left(\mathrm{AvEC}_{\mathrm{k}}\right)$ in Athens is $0.762 € / \mathrm{km}$ for the diesel bus and $0.138 € / \mathrm{km}$ for the bus fueled by natural gas.

The two candidate buses are the same model (except that they fueled by different fuels) of a European manufacturer. According to the technical data sheet given by the manufacturer, the emissions of the air pollutants associated with the use of both of them are presented in Table 2. Regarding the fuel consumption and the $\mathrm{CO}_{2}$ emissions, the manufacturer does not provide any direct information. As for the first, however, the average energy consumption of a full bus in the area of Athens is, according to the literature [20], $3 \mathrm{kWh} / \mathrm{km}$ or $10.8 \mathrm{MJ} / \mathrm{km}$. Accepting here this figure as the average energy consumption of a diesel bus, the relevant figure for a gas fueled bus becomes 3.183 $\mathrm{kWh} / \mathrm{km}$ or $11.459 \mathrm{MJ} / \mathrm{km}$, since it is increased by the ratio $15.83 / 14.92$ indicated by the literature [17], corresponding to the lower efficiency of gas engines. Subsequently, from the average energy consumption data and the appropriate fuel production and 
Table 4: Air Pollutants' Emissions in g/km Associated with the Production and Distribution of the Consumed Fuel for the Two Candidate Buses

\begin{tabular}{lcc}
\hline Air pollutant & Diesel bus & Natural gas bus \\
\hline Carbon dioxide $\left(\mathrm{CO}_{2}\right)$ & 73.44 & 46.98 \\
Carbon monoxide $(\mathrm{CO})$ & 0.053 & 0.016 \\
Methane $\left(\mathrm{CH}_{4}\right)$ & 0.171 & 2.563 \\
Non-Methane Volatile Organic Compounds (NMVOC) & 0.951 & 2.607 \\
Nitrogen oxides $\left(\mathrm{NO}_{\mathrm{x}}\right)$ & 0.401 & 0.122 \\
Sulphur dioxide $\left(\mathrm{SO}_{2}\right)$ & 0.490 & 0.134 \\
Particulate matters $(\mathrm{PM})$ & 0.012 & 0.009 \\
\hline
\end{tabular}

Table 5: Total Emissions of Air Pollutants in $\mathrm{g} / \mathrm{km}$ for the Two Candidate Buses

\begin{tabular}{lcc}
\hline Air pollutant & Diesel bus & Natural gas bus \\
\hline Carbon dioxide $\left(\mathrm{CO}_{2}\right)$ & 650.42 & 475.50 \\
Carbon monoxide $(\mathrm{CO})$ & 9.053 & 6.891 \\
Methane $\left(\mathrm{CH}_{4}\right)$ & 2.121 & 2.611 \\
Non-Methane Volatile Organic Compounds (NMVOC) & 2.151 & 2.620 \\
Nitrogen oxides $\left(\mathrm{NO}_{\mathrm{x}}\right)$ & 6.401 & 1.491 \\
Sulphur dioxide $\left(\mathrm{SO}_{2}\right)$ & 0.490 & 0.194 \\
Particulate matters $(\mathrm{PM})$ & 0.072 & 0.019 \\
\hline
\end{tabular}

Table 6: Ecological Coefficients $\left(\mathrm{EC}_{\mathrm{i}, \mathrm{k}}\right)$ for the Two Candidate Buses

\begin{tabular}{lcc}
\hline Environmental impact $(\mathrm{i})$ & Diesel bus $(\mathrm{k}=1)$ & Natural gas bus $(\mathrm{k}=2)$ \\
\hline Carbon dioxide $(\mathrm{i}=1)$ & 0.388 & 0.278 \\
Carbon monoxide $(\mathrm{i}=2)$ & 1.331 & 1.130 \\
Methane (i=3) & 2.651 & 0.170 \\
Non-Methane Volatile Organic Compounds (i=4) & 0.545 & 1.794 \\
Nitrogen oxides (i=5) & 0.242 & 0.177 \\
Sulphur dioxide (i=6) & 0.144 & 0.075 \\
Particulate matters (i=7) & 0.091 & 0.134 \\
\hline
\end{tabular}

distribution emission factors reported in the literature $[17,21]$ and presented in Table 3, the air pollutants' emissions associated with the production and distribution of the consumed fuel for each candidate bus is calculated and presented in Table 4. As for the $\mathrm{CO}_{2}$ emissions during the use of each bus, the relevant emission factor for conventional diesel urban buses in Europe is $576,98 \mathrm{~g} / \mathrm{km}$ [22], while the same factor for gas fueled bus is not available since this technology is little used till now and measured data are rare. However, according to the literature [23] the $\mathrm{CO}_{2}$ emission of natural gas consumed is about $30 \%$ less than this of diesel (per equivalent energy content). Thus, considering also the above mentioned ratio $15,83 / 14,92$, the $\mathrm{CO}_{2}$ emission factor for a natural gas fueled gas becomes $428.52 \mathrm{~g} / \mathrm{km}$.

Combining Table 4 with Table 2 (and considering also the data concerning the average energy consumption and the $\mathrm{CO}_{2}$ emissions during the use phase of the two buses), the total emissions of air pollutants for the candidates are calculated in Table 5. It must be noticed that the emissions due to the fabrication of the buses as well as the disposal of them at the end of their useful life are not included in Table 5. Nevertheless, given that there no reason why there would be any significant difference in emissions between the two types of bus due to their fabrication and disposal phase (the two candidates are almost similar models made by the same manufacturer), these two phases are not considered here.

\section{RESULTS}

Having collected all necessary data, it is now easy to apply the proposed model as follows:

Applying the equation 1 for $\mathrm{n}=7$ ( $\mathrm{i}=1$ for $\mathrm{CO}_{2}, \mathrm{i}=2$ for $\mathrm{CO}, \mathrm{i}=3$ for $\mathrm{CH}_{4}, \mathrm{i}=4$ for NMVOC, $\mathrm{i}=5$ for $\mathrm{NO}_{\mathrm{x}}, \mathrm{i}=6$ for $\mathrm{SO}_{2}$ and $\mathrm{i}=7$ for $\left.\mathrm{PM}\right)$ and $\mathrm{r}=2(\mathrm{k}=1$ for diesel bus and $\mathrm{k}=2$ for gas fueled bus), one can calculate the ecological coefficients $\left(\mathrm{EC}_{\mathrm{i}, \mathrm{k}}\right)$ for each candidate (Table 6). In this equation, the required environmental impacts $\left(\mathrm{EI}_{\mathrm{i}, \mathrm{k}}\right)$ are given in Table 5, while the average environmental impacts $\left(\mathrm{AvEI}_{\mathrm{i}, \mathrm{k}}\right)$ are given in Table 1. Afterwards, applying the equations 2 and 3 and using the data of Table 6 , the ecological grade $\left(\mathrm{EG}_{\mathrm{k}}\right)$ for each candidate is calculated:

$\mathrm{EG}_{1}$ (diesel bus) $=0.770$ and $\quad \mathrm{EG}_{2}$ (natural gas fueled bus) $=0.680$ 
Finally, applying the equation 4 and based on the above ecological grades as well as on the average External Costs $\left(\mathrm{AvEC}_{\mathrm{k}}\right)$ estimated previously, the relative External Cost $\left(\mathrm{REC}_{\mathrm{k}}\right)$ for the two buses is calculated:

$\mathrm{REC}_{1}$ (diesel bus) $=0.587 € / \mathrm{km}$ and $\mathrm{REC}_{2}$ (natural gas fueled bus) $=0.094 € / \mathrm{km}$

These two values are used in a typical supplier selection model as a criterion together with other ones concerning the technical and commercial features of the two candidates. Alternatively, they can be used in TCObased decision model as follows: given that in Greece the total annual mileage per vehicle for urban buses is about $16904 \mathrm{~km} / \mathrm{yr}$ and that the mean passenger vehicle age is about 10,2 year [24], the total environmental external cost occurred during the useful life time of the two buses is 101.211,01 $€$ for the diesel bus and $16.207,56 €$ for the gas fuelled bus (we have assumed that the mean urban bus age is about 10,2 year as well). These values can be taken into consideration in a TCO model, together with all other costs that incurred throughout the life cycle of the two buses, to assist the final choice by modifying their price accordingly.

\section{DISCUSSION}

The present study proposes a procedure for considering the environmental externalities in technology selection decision-making. Currently, there are several methods available for supplier selection and purchasing decision-making, most of which could be used in the technology selection process as well. However, all of them consider factors that seem to focus almost exclusively on what creates most net value to the buyer of a technology system, ignoring the external costs associated with this system. In this context, the proposed here method has been developed in order to provide a tool for the integration of the environmental externalities in the technology selection process. This tool is based on the findings of Life Cycle Assessments. The main advantages and disadvantages of this method are the following: At first, it is not sophisticated, as it is easy to understand and easy to use. Moreover, it is not very data and effort consuming. Regarding the latter, the required data for the application of the procedure is the environmental performance of the candidates as well as information concerning the average external cost in a particular area and the associated with this cost environmental burden of a typical, similar to the candidates, product or process. LCA findings can be used as a good source for the environmental performance of the candidates, while the general literature can provide information on the environmental externalities for a steadily growing number of products, processes and activities. Even if this information concerns particular geographical areas, it can be, relatively easily, transferred to other ones as rough estimation, but of sufficient accuracy. Another positive point of the method is its flexibility since it can be incorporated in most of the traditional supplier selection decision models. Specifically, the outcome of the proposed here procedure could be considered, together with all other costs, in a total cost of ownership model adjusting the price offered, or it could be included in a linear weighting model as one of the criteria used. Aside from the above, it can also be used as the exclusive base for the comparative appraisal of the candidates. In such a case, this method allows a clear conclusion as it leads to single value (the relative external cost), which is unambiguously comparable. Apparently, this could be considered as another advantage of the proposed method. Regarding the drawbacks of the method, one could mention that it heavily depends on the quality of the information used, especially this one that concerns the external cost. In certain cases, uncertainties of this information may be considerable, because there are not enough measured data while the available form various sources data are not always consistent. There are numerous sources of uncertainty in this kind of information. Some of the more important include old data, incomplete data, missing data, data aggregation etc. It is evident that all these sources of uncertainty may affect the outcome of the method.

A comparative appraisal application is also presented in the study to show the proposed framework. It is about the comparison of two urban buses for the city of Athens, of different fuel technology: the first one fueled by diesel and the other fueled by natural gas. In this application, the method has been successfully applied helping to identify which of them has the lowest environmental external cost as well as to show better some of the strong and weak features of the proposed method. The result of this application is a single value for each candidate that can be easily incorporated in almost any common decision-making model, which intends to take into consideration the externalities of its choice.

\section{REFERENCES}

1. Janszen, F., 2000. The Age of Innovation. Published by Financial Times/Prentice Hall, London.

2. Chan, F.T.S., M.H. Chan and N.K.H. Tang, 2000. Evaluation methodologies for technology selection. J. Mater. Process. Technol., 107: 330-337.

3. De Boer, L., E. Labro and P. Morlacchi, 2001. A review of methods supporting supplier selection. European J. Purchasing and Supply Manage., 7: 75-89.

4. Shtub, A., J.F. Bard and S. Globershon, 1994. Project Management-Engineering, Technology and Implementation. Published by Prentice Hall International Editions, London. 
5. Verter, V., 2002. An integrated model for facility location and technology acquisition. Computers and Operations Res., 29: 583-592.

6. Verter, V. and A. Dasci, 2002. The plant location and flexible technology acquisition problem. European J. Oper. Res., 136: 366-382.

7. Field, B.C., 1997. Environmental Economics-An Introduction. Published by McGraw Hill Int. Eds., New York.

8. Callan, S.J. and L.M. Thomas, 2000. Environmental Economics and ManagementTheory, Policy and Applications. Published by the Dryden Press, Orlando.

9. Matthews, H.S., 2002. Use versus manufacture life cycle electricity and environmental impacts for computer tape drives. Resources, Conservation and Recycling, 36: 187-196.

10. Goedkoop, M. and M. Oele, 2001. Introduction into LCA Methodology and Practice with SimaPro 5. Published by PRé Consultants, Amersfoort.

11. Georgakellos, D.A., 2002. LCA as a tool for environmental management: A life cycle inventory case study from the Greek market. Global Nest: The Intl. J., 4: 93-105.

12. Lave, L.B. and E. Cobas-Flores, 1995. Using inputoutput analysis to estimate economy-wide discharges. Environ. Sci. Technol., 29: 420A426A.

13. Hendrickson, C., A. Horvath, S. Joshi and L. Lave, 1998. Economic input-output models for environmental life-cycle assessment. Environ. Sci. Technol., 32: 184A-191A.

14. Banfi, S., C. Doll, M. Maibach, W. Rothengatter, P. Schenkel, N. Sieber and J. Zuber, 2000. External Costs of Transport-Accident, Environmental and Congestion Costs in Western Europe. Published by INFRAS/IWW, Zürich/Karlsruhe.
15. Bickel, P., S. Schmid, W. Krewitt and R. Friedrich, 1997. External Costs of Transport in ExternE. Published by IER, Stuttgart.

16. LIEE/NTUA, 1997. External Costs of Electricity Generation in Greece. Published by National Technical University of Athens, Athens.

17. Rabl, A., 2002. Environmental benefits of natural gas for buses. Transport. Res. Part D., 7: 391-405.

18. European Environment Agency, 2001. External Costs of Transport: Version 20-08-2001. Published by EEA, Copenhagen.

19. Vossiniotis, G. and D. Assimakopoulos, 1999. The marginal environmental costs of transport in Greece. Global Nest: The Intl. J., 1: 77-89.

20. Georgiou, P., 1995. Electric or Thermal Bus in Urban Transportation?-A Comparison (in Greek). Technica Chronica, 2: 29-32.

21. Lewis, C.A., 1997. Fuel and Energy Production Emission Factors: Deliverable No. 20 MEET Project. Published by European Commission.

22. Cox, J.A. and A.J. Hickman, 1998. Aggregated emission factors for road and rail transport: Deliverable No. 23 EET Project. Published by European Commission.

23. Theodosiou, T., G. Kostopoulos, G. Polychroniou, C. Samaras and N. Psigas, 2003. The Natural Gas and its Applications (in Greek). Published by DEPA, Athens.

24. LAT/AUTH, 1998. Methodologies for Estimating Air Pollutant emissions from Transport. Road Traffic Composition, LAT Report No: 9823. Published by Aristotle University of Thessaloniki, Thessaloniki. 